Special Issue: Gravity Responses and The Cell Wall in Plants

\section{Modification of Cell Wall Architecture in Gramineous Plants under Altered Gravity Conditions}

\author{
Kazuyuki Wakabayashi ${ }^{\dagger}$, Kouichi Soga \\ and Takayuki Hoson \\ Department of Biology and Geosciences, Graduate \\ School of Science, Osaka City University, Osaka \\ 558-8585, Japan
}

\begin{abstract}
Gramineous plants, such as rice, wheat, and maize, are essential crops. The cell wall composition of gramineous plants is distinguished from that of dicotyledons, such as Arabidopsis, pea, and mung bean. In cell walls of gramineous plants, arabinoxylans and $\beta$-glucans are the major matrix polysaccharides and they make network structure within cell wall architecture. Gravitational stimuli affect the metabolism of $\beta$-glucans in gramineous shoots; hypergravity suppressed the $\beta$-glucan breakdown, when it inhibited shoot elongation. The opposite results were obtained under microgravity conditions in space. On the other hand, the arabinoxylan and diferulic acid (DFA) contents increased under continuous hypergravity conditions. Since arabinoxylans are cross-linked by DFA-bridges, continuous hypergravity may stimulate the formation of arabinoxylan-DFA network within cell walls. These findings suggest that the $\beta$-glucan metabolism is primarily involved in the mechanism of growth regulation, while the arabinoxylan-DFA network has a load-bearing function against the gravitational force. The modification of these wall constituents may contribute to the capacity of gramineous plants to sustain their structure and growth under altered gravity conditions. (02009 Jpn. Soc. Biol. Sci. Space; Article ID: 092303015
\end{abstract}

\section{Introduction}

Plants are subjected to a variety of environmental stimuli, such as gravity, light, temperature, water, and wind, and these stimuli strongly influence the processes of plant growth and development. Of these signals, gravity is always present on the earth in a constant direction and magnitude. Since terrestrial plants have evolved in the presence of gravity, they have developed the cell

Received: June 25, 2009; Accepted:July 23, 2009

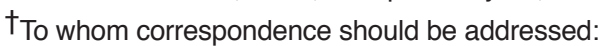
Tel.: +81-66605-3150; Fax: +81-66605-2577; E-mail: wakaba@sci.osaka-cu.ac.jp wall to support and stand upright their body against the gravitational force at $1 G$, as do the bones and muscles in an animal body (Hoson and Soga, 2003). Cell walls provide the protoplasts with the structural (mechanical) rigidity and determine directly the size and shape of plant cells. Thus, they play an important role in the regulation of plant growth and morphogenesis (Taiz, 1984; Hoson, 2002).

Flowering plants are usually divided into two groups, based partly on the number of cotyledon, or seed leaves, in the embryo. Species with one cotyledon are called monocotyledons, and those with two are called dicotyledons. Gramineous plants, such as rice, maize, wheat, barley, and oat, are essential crops and classified into monocotyledons. Plant cell walls are composed of cellulose, a variety of matrix polysaccharides, proteins and phenolic substances (Carpita and Gibeaut, 1993). The amount and structure of wall constituents are involved in determining the rigidity of the cell wall (Taiz, 1984). Depending on the matrix polysaccharide composition, the cell wall of gramineous plants (Type II walls, Fig. 1) is distinguished from that of dicotyledons and other monocotyledons (most common type of cell wall, Type I walls) by having a low content of pectic polymers and xyloglucans while a high content of arabinoxylans and $\beta-1,3: 1,4$-glucans ( $\beta$-glucans) (Carpita and Gibeaut, 1993; Carpita, 1996). Arabinoxylans and $\beta$-glucans are the major matrix polysaccharides in the cell wall of gramineous plants and they make network structure between cellulose microfibrils. Also, the amounts of arabinoxylans and $\beta$-glucans show dynamic changes during growth and development (Sakurai et al., 1983; Wakabayashi et al., 1997a; Obel et al., 2002). In addition to polysaccharides, cell walls of gramineous plants contain a significant amount of phenolic acid (hydroxycinnamate) monomers such as feruric acid (FA) and $p$-coumaric acid, which are bound to arabinoxylans (Smith and Hartley, 1983; Saulnier and Thibault, 1999). Of these phenolics, FA undergoes a coupling reaction to produce diferulic acid (DFA), which cross-links arabinoxylans (Fry, 1986; Grabber et al., 1995; Saulnier et al., 1999). Thus, the formation of arabinoxylanDFA cross-links makes a rigid network within cell wall architecture (Fry, 1986; Carpita and Gibeaut, 1993). The level of wall-bound DFA has been shown to be involved in determining the rigidity of cell walls in gramineous plants (Kamisaka et al., 1990; Tan et al., 1991; Parvez et al., 1997; Wakabayashi et al., 1997b). In the present article, we describe the quantitative and qualitative changes of cell wall constituents, particularly $\beta$-glucans, arabinoxylans, and cell wall-bound hydroxycinnamates, in gramineous plants grown under altered gravity conditions and discuss the roles of these constituents in adaptation mechanism of plants to the gravitational stimuli.

\section{Cell wall polysaccharides (matrix polysaccharides)}

\section{$\beta$-1,3:1,4-Glucans ( $\beta$-Glucans)}

$\beta-1,3: 1,4-G l u c a n s$ are linear, unbranched polymers of $D$-glucose residues linked $\beta-1,3$ and $\beta-1,4$, and are 


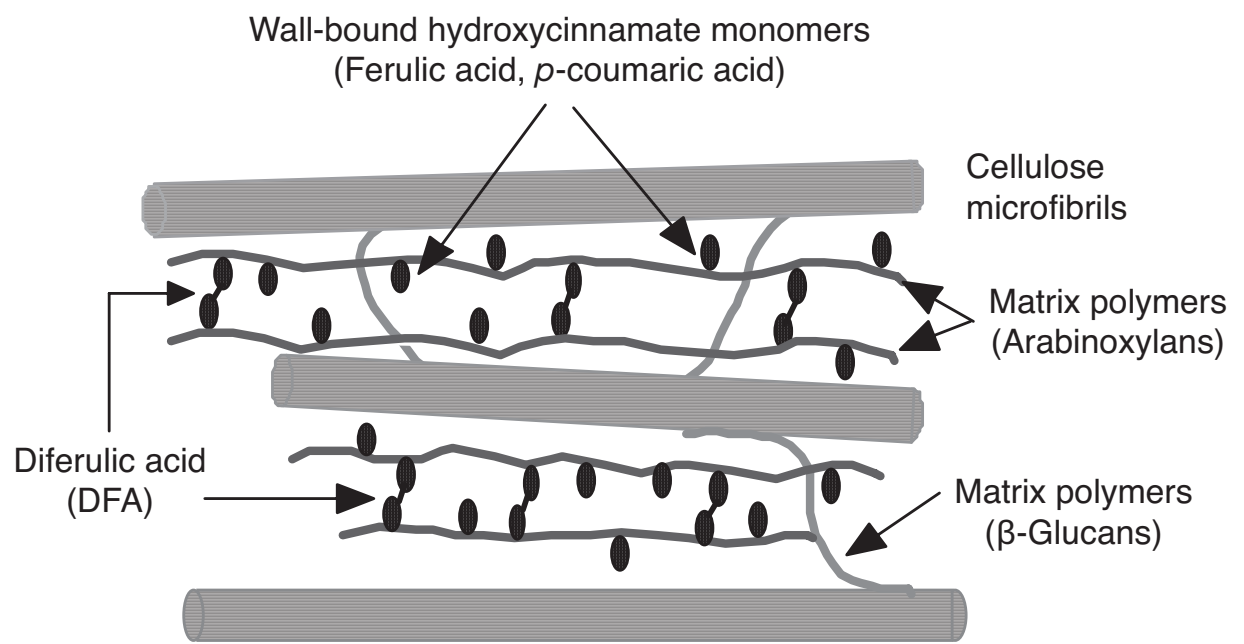

Fig. 1. A schematic illustration of the cell wall of gramineous plants. Matrix polysaccharides, particularly arabinoxylans and $\beta$-glucans, make a complex network structure between cellulose microfibrils.

characteristic of the cell wall of gramineous plants. They consist primarily of cellotriosyl and cellotetrasyl units linked by single $\beta-1,3$ linkages (Carpita and Gibeaut, 1993). The $\beta-1,4$-linked residues within the structure tend to form extended, ribbon-like configuration, but the $\beta-1,3$ links introduce kinks into the structure. The polysaccharides also contain a small portion of long stretches of $\beta-1,4-$ linked residues (Kato and Nevins, 1984), which enables the polymer to interact with other $\beta$-glucans and cellulose microfibrils by hydrogen bonding. Gramineous $\beta$-glucans are high molecular mass polymers; the weight average molecular mass is higher than $1 \mathrm{MDa}$. (Sakurai, 1991; Hoson, 2002). Therefore, $\beta$-glucans may cause a high viscous state of cell walls and contribute to the regulation of mechanical properties of the cell wall.

$\beta$-Glucans in intact shoots show dynamic changes during growth. In wheat shoots, the $\beta$-glucan content increased with shoot elongation, but it decreased after the cessation of elongation (Fig. 2, Wakabayashi et al., 1997a; Obel et al., 2002). Also, decreases in the $\beta$-glucan content are observed in shoot segments of gramineous seedlings, when auxin induces the cell wall loosening (an increase in the cell wall extensibility) and thus segment elongation (Masuda, 1990; Sakurai, 1991; Hoson, 1993). Correlations exist among auxin-induced decrease in the $\beta$-glucan content, changes in the mechanical properties of the cell wall, and segment elongation. Furthermore, antibodies raised against $\beta-1,3: 1,4$-glucans and also $\beta-1,3: 1,4-$ glucan hydrolases (glucanases) inhibited auxin-induced elongation of shoot sections and cell wall loosening as well as the breakdownn of $\beta$-glucans (Hoson and Nevins, 1989; Inouhe and Nevins, 1991). In addition, environmental stimuli, such as the light irradiation and the low and high temperatures, lowered the activity of $\beta-1,3: 1,4$-glucanases in rice shoots, when they suppressed the shoot elongation (Chen et al., 1999; Nakamura et al., 2003). These findings indicate that the metabolism of $\beta$-glucans is related to the regulation of growth, acting as a temporary cross-linker of cellulose microfibrils during cell wall expansion. Particularly, the degradation of $\beta$-glucans by glucanases is associated with the cell wall loosening that is responsible for cell elongation.

In order to clarify the role of gravity on the construction of cell wall architecture, it is effective to examine the changes in cell wall structure under different gravitational conditions. Experiments with centrifugation techniques conveniently provide hypergravity conditions, the gravitational forces of more than $1 G$ (Hoson and Soga, 2003). Soga et al. (1999) showed that hypergravity $(300 \mathrm{G})$ treatment for several hours decreased the cell wall extensibility of maize shoots, when it inhibited elongation growth. They also showed that the $\beta-1,3: 1,4-$ glucanase activity in maize shoots decreased and the relative content of high molecular mass portion in the hemicellulosic (matrix) polysaccharides (mainly high molecular mass $\beta$-glucans) increased under hypergravity conditions, although hypergravity did not affect the net amounts of hemicellulosic polysaccharides. In addition, the changes in the growth rate, the cell wall extensibility, the relative content of high molecular mass $\beta$-glucans, and the $\beta-1,3: 1,4$-glucanase activity in maize shoots by hypergravity for several hours recovered fully and promptly by the removal of hypergravity stimuli (Soga et al., 2003). These results indicate that the suppression of $\beta$-glucan breakdown is involved in the inhibition of elongation growth under hypergravity conditions. On the other hand, opposite results were observed under microgravity conditions in space; the length and cell wall extensibility of space-grown rice shoots were larger than those of ground-grown ones (Hoson et al., 2002; 2004). Also, microgravity conditions increased the activity of $\beta-1,3: 1,4-$ glucanases and decreased the relative content of high molecular mass $\beta$-glucans in rice shoots (Hoson et al., 2002; 2004). Therefore, it appears that gravity 

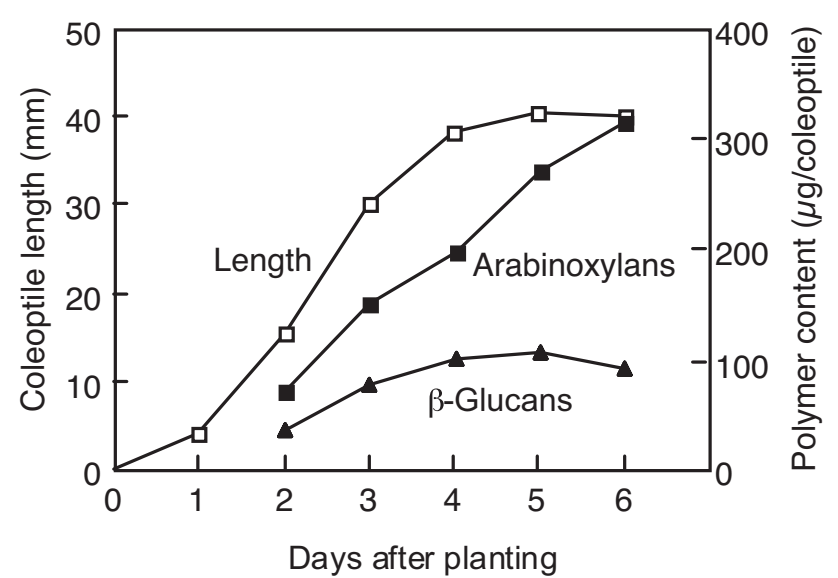

Fig. 2. Changes in arabinoxylan and $\beta$-glucan contents during growth of wheat shoots. Data are modified from Wakabayashi et al. (1997a).

stimuli primarily modify the $\beta$-glucan metabolism, when they alter the growth rate of gramineous shoots.

\section{Arabinoxylans (glucuronoarabinoxylans)}

Arabinoxylans of gramineous plants have a backbone consisting of $\beta-1,4$-linked $D$-xylose residues, which can be substituted to some extent with side chains (Carpita and Gibeaut, 1993). The most common side chain is a single arabinose residue and the second most common one is a single glucuronic acid residue, therefore arabinoxylans possess a nature of acidic polymer. In addition, some arabinose residues are further substituted with hydroxycinnamate monomers, such as FA and $p$-coumaric acid. FA residue undergoes a coupling reaction to produce DFA, which cross-links arabinoxylan molecules. Therefore, gramineous arabinoxylans are thought to form a tight network within cell wall architecture via DFA-bridges (Fry, 1986).

Unlike $\beta$-glucans, the arabinoxylan content in wheat shoots continued to increase after the cessation of shoot elongation (Fig. 2). Therefore, arabinoxylans are largely deposited in the mature walls than in the young, extensible walls of gramineous plants. Furthermore, shoots of a dwarf mutant of barley, which had a thickened cell wall, contained large amounts of arabinoxylans (Sakurai et al., 1983). Also, when submerged (watergrown) rice shoots were transferred to air conditions, the rigidity of shoot cell walls rapidly increased concomitant with the increase in arabinoxylan content (Kawamura et al., 2000). Recently, Mélida et al. (2009) showed that DCB (2,6-dichlorobenzonitril), a potent inhibitor of cellulose synthesis, substantially reduced the cellulose content in cell walls of maize callus-culture cells, and that in DCB-habituated cells, the reduction of cellulose content was compensated for by a net increase in arabinoxylan content. According to the cell wall model, temporal crosslinks by $\beta$-glucans are finally replaced by arabinoxylans (Carpita and Gibeaut, 1993). Therefore, it is likely that arabinoxylan network possesses a load-bearing function and an increase in arabinoxylan content contributes to making a stiffer cell wall architecture.

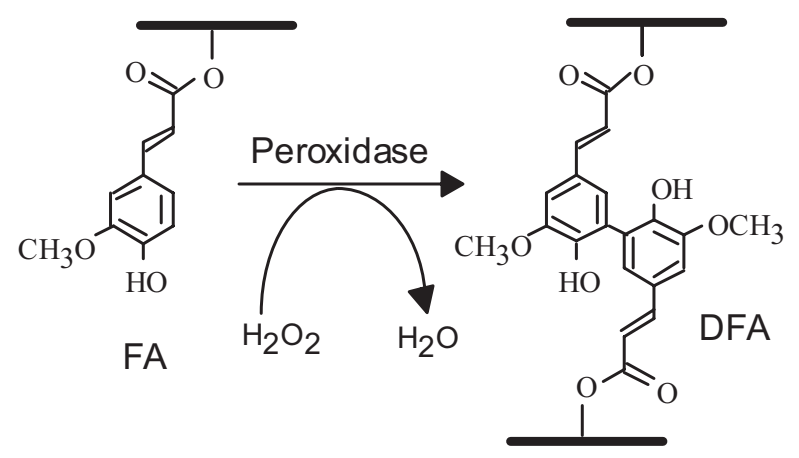

Fig. 3. A schematic illustration of the formation of polysaccharide-DFA cross-link in the cell wall of gramineous plants.

The hypergravity (300 G) treatment for several hours did not affect the net amounts of matrix polysaccharides (Soga et al., 1999). In contrast, hypergravity for several days (continuous hypergravity treatment) increased the net amounts of arabinoxylans in wheat shoots, while it did not affect the $\beta$-glucan content (Wakabayashi et al., 2005a). These results suggest that continuous (prolonged) hypergravity biases the type of synthesized matrix polysaccharides; especially it stimulates the synthesis of arabinoxylans. The increase in the arabinoxylan content under continuous hypergravity conditions may promote the transition of the cell wall from a flexible to a more rigid structure. On the other hand, the effect of microgravity conditions on the arabinoxylan content in gramineous plants has been limited. Stutte et al. (2006) reported that the cross-sectional thickness of wheat leaves which had been grown for three weeks under microgravity conditions in space decreased as compared with that of $1 \mathrm{G}$ ground controls. They also showed that the arabinose and xylose contents in cell walls of space grown leaves were slightly lower than those of ground controls. It is likely that prolonged microgravity treatment suppresses the arabinoxylan synthesis. Urahara et al. (2004) reported that the activities of xylosyltransferases are closely associated with the synthesis of arabinoxylans in developing barley endosperms. Therefore, gravitational stimuli may modify such enzyme activities, when they alter the arabinoxylan levels.

\section{Cell Wall-bound phenolic acids}

In gramineous cell walls, hydroxycinnamate monomers, such as FA and p-coumaric acid, are esterbound to arabinose residues of arabinoxylans as described above. Usually, $p$-coumaric acid was much less abundant than FA (Parvez et al., 1997; Obel et al., 2002). A certain portion of FA undergoes a peroxidase-catalyzed coupling reaction to produce DFA (Fig. 3, Fry, 1986; Grabber et al., 1995; Saulnier et al., 1999). DFA directly contributes to the formation of arabinoxylan network within cell wall architecture. 


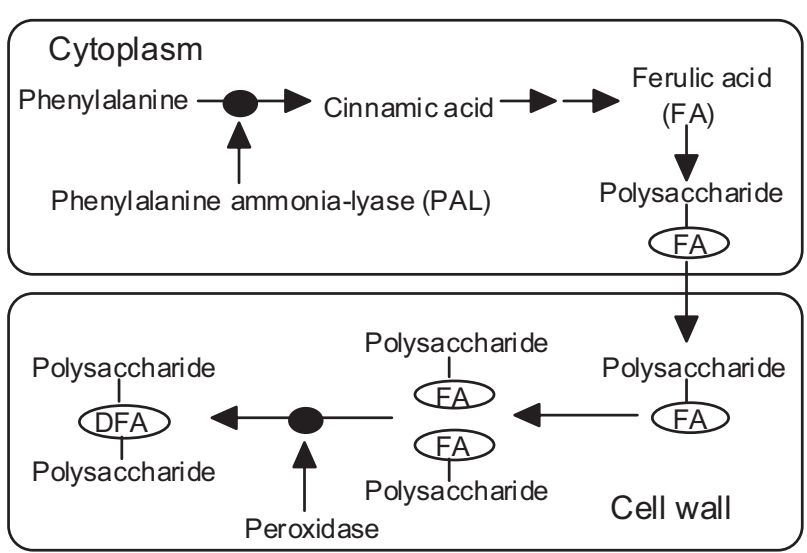

Fig. 4. The synthetic pathway of FA (ferulic acid) and DFA (diferulic acid).

DFA content in gramineous shoots increased greatly during shoot growth (Kamisaka et al., 1990; Tan et al., 1991; Parvez et al., 1997; Wakabayashi et al., 1997b; 1997c; Obel et al., 2002). Environmental stimuli, such as the light irradiation (Tan et al., 1992; Miyamoto et al., 1994; Parvez et al., 1997), water submergence (Tan et al., 1991; Kawamura et al., 2000), and water deficiency (Wakabayashi et al., 1997b; 1997c), and a plant hormone, abscisic acid (Wakabayashi et al., 1997d), affected the formation of DFA in rice, maize, oat, and wheat shoots. These results show that an increase in DFA content is closely correlated with an increase in the cell wall rigidity, while the reduced amount of DFA participates in maintaining the extensible walls. Thus, the formation of DFA plays an important role in determining the cell wall mechanical strength and also contributes to keeping cell wall architecture in gramineous plants.

As shown in Fig. 3 and Fig. 4, DFA is synthesized by the coupling reaction of FA residues. In many cases, the DFA content has been shown to change in parallel with the FA content (Kamisaka et al., 1990; Tan et al., 1991; Parvez et al., 1997; Wakabayashi et al., $1997 b)$. Therefore, the rate of the formation of DFA in cell walls may be attributed to the synthesis of FA. FA is synthesized via the phenylpropanoid pathway, and phenylalanine ammonia-lyase (PAL) catalyzes the first step and plays a rate-limiting role in the pathway (Fig. 4, Whetten and Sederoff 1995). The involvement of PAL activity in the regulation of the level of cell wallbound FA has been shown in wheat (Wakabayashi et al., 1997b; 1997d), maize (Parvez et al., 1997), and oat shoots (Hossain et al., 2007). In addition to PAL, cell wallbound (apoplastic) peroxidases have been considered to catalyze the coupling reaction of FA. Recently, we found that the activity of cell wall-bound peroxidase substantially increased during growth of rice shoots and that there was a close correlation between the DFA content and the enzyme activity (unpublished results). These findings suggest that both PAL and wall-bound peroxidase are involved in the regulation of the DFA formation in gramineous shoots.
Similar to the arabinoxylan content, continuous hypergravity treatment ( $300 \mathrm{G}$ for 2-4 days) significantly increased the DFA content in cell walls of wheat shoots (Wakabayashi et al., 2005a). Particularly, the amounts of DFA in shoots that had been grown for 3 and 4 days under hypergravity conditions were twice of those in the controls. In addition, the amounts of DFA per unit arabinoxylan content were higher in hypergravity-treated shoots than in the controls, indicating that continuous hypergravity treatment increased the number of DFAbridges in arabinoxylan molecule; each arabinoxylan molecule in control and hypergravity-treated shoots possessed about 5 and 10 DFA molecules, respectively (Wakabayashi et al., 2005a). Therefore, such an increase in DFA may strengthen the arabinoxylan network and enhance resistance to the gravitational force. Abovementioned results also suggest that hypergravity stimulates the synthesis of hydroxycinnamates. Indeed, a certain period of hypergravity treatment increased the activity of PAL in wheat shoots (Wakabayashi et al., $2005 b$ ). The ratio of DFA to FA in cell walls of wheat shoots largely increased under continuous hypergravity conditions (Wakabayashi et al., 2005a), suggesting that hypergravity stimulates the coupling reaction of FA catalyzed by wall-bound peroxidases (Fig. 3). In stem tissues of dicotyledons, such as azuki bean seedlings, we have reported that hypergravity increased the activity of wall-bound peroxidase, when it increased the amounts of lignin, a complex phenolic polymer formed by the polymerization of hydroxycinnamates (Wakabayashi et al., 2009). Therefore, the increases in the activities of PAL and possibly wall-bound peroxidases in response to hypergravity stimuli may be involved in the promotion of DFA formation in gramineous plants.

On the other hand, the effects of microgravity on the DFA formation in gramineous plants have not been investigated. Furthermore, the effect of microgravity on the formation of lignin is controversial; Cowles et al. (1989) showed that the lignin formation was suppressed under microgravity conditions in space, while Levine et al. (2001) reported that there were no significant differences in lignin content between space- and ground-grown wheat seedlings. Further studies are required in order to clarify these subjects. We are planning a space experiment termed "FERULATE", in which the levels of cell wall phenolic components including FA, DFA, and also lignin, and the gene expression level and the activity of enzymes that are related to the synthesis of phenolic components in gramineous plants are examined under microgravity conditions in space.

\section{References}

Carpita, N.C. and Gibeaut, D.M. (1993) Structural model of the primary cell walls in flowering plants: consistency of molecular structure with the physical properties of the walls during growth, Plant J., 3, 1-30.

Carpita, N.C. (1996) Structure and biogenesis of the cell walls of grasses, Ann. Rev. Plant Physiol. Plant Mol. Biol., 47, 445-476. 
Chen, L., Kamisaka, S. and Hoson, T. (1999) Suppression of $(1 \rightarrow 3),(1 \rightarrow 4)-\beta$-D-glucan turnover during lightinduced inhibition of rice coleoptile growth, J. Plant Res., 112, 7-13.

Cowles, J.R., LeMay, R., Jahns, G., Scheld, W.H. and Peterson, C. (1989) Lignification in young plant seedlings grown on earth and aboard the space shuttle. In Plant Cell Wall Polymers. Biogenesis and Biodegradation. ACS Symposium Series 399 (ed. Lewis, N.G. and Paice, M.G.), pp 203-213. Washington DC, American Chemical Society.

Fry, S.C. (1986) Cross-linking of matrix polymers in the growing cell walls of angiosperms, Annu. Rev. Plant Physiol., 37, 165-186.

Grabber, J.H., Hatfield, R.D., Ralph, J., Zon, J. and Amrhein, N. (1995) Ferulate cross-linking in cell walls isolated from maize cell suspensions, Phytochemistry, 40, 1077-1082.

Hoson, T. and Nevins, D.J. (1989) $\beta-D-G l u c a n$ antibodies inhibit auxin-induced cell elongation and changes in the cell walls of Zea coleoptile segments, Plant Physiol., 90, 1353-1358.

Hoson, T. (1993) Regulation of polysaccharide breakdown during auxin-induced cell wall loosening, J. Plant Res., 106, 369-381.

Hoson, T. (2002) Physiological functions of plant cell coverings, J. Plant Res., 115, 277-282.

Hoson, T., Soga, K., Mori, R., Saiki, M., Nakamura, Y., Wakabayashi, K. and Kamisaka, S. (2002) Stimulation of elongation growth and cell wall loosening in rice coleoptiles under microgravity conditions in space, Plant Cell Physiol., 43, 1067-1071.

Hoson, T. and Soga, K. (2003) New aspects of gravity responses in plant cells, Int. Rev. Cytol., 229, 209-244.

Hoson, .T, Soga, K., Mori, R., Saiki, M., Nakamura, Y., Wakabayashi, K. and Kamisaka, S. (2004) Cell wall changes involved in the automorphic curvature of rice coleoptiles under microgravity conditions in space, $\mathrm{J}$. Plant Res., 117, 449-455.

Hossain, M.T., Soga, K., Wakabayashi, K., Kamisaka, S., Fujii, S., Yamamoto, R. and Hoson, T. (2007) Modification of chemical properties of cell walls by silicon and its role in regulation of the cell wall extensibility in oat leaves, J. Plant Physiol., 164, 385393.

Inouhe, M. and Nevins, D.J. (1991) Inhibition of auxininduced cell elongation of maize coleoptiles by antibodies specific for cell wall glucanases, Plant Physiol., 96, 426-431.

Kamisaka, S., Takeda, S., Takahashi, K. and Shibata, K. (1990) Diferulic and ferulic acid in the cell wall of Avena coleoptiles - Their relationships to mechanical properties of the cell wall, Physiol. Plant., 78, 1-7.

Kato, Y. and Nevins, D.J. (1984) Enzymic dissociation of Zea shoot cell wall polysaccharides. II. Dissociation of $(1 \rightarrow 3),(1 \rightarrow 4)-\beta$-D-glucan by purified $(1 \rightarrow 3),(1 \rightarrow 4)-\beta-D-g l u c a n$ 4-glucanohydrolase from Bacillus subtilis, Plant Physiol., 75, 745-752.
Kawamura, Y., Wakabayashi, K., Hoson, T., Yamamoto, R. and Kamisaka, S. (2000) Stress-relaxation analysis of submerged and air-grown rice coleoptiles: Correlations with cell wall biosynthesis and growth, J. Plant Physiol., 156, 689-694.

Levine, L.H., Heyenga, A.G., Levine, H.G., Choi, J.W., Davin, L.B., Krikorian, A.D. and Lewis, N.G. (2001) Cell-wall architecture and lignin composition of wheat developed in a microgravity environment, Phytochemistry, 57, 835-846.

Masuda, Y. (1990) Auxin-induced cell elongation and cell wall changes, Bot. Mag. Tokyo, 103, 345-370.

Mélida, H., García-Angulo, P., Alonso-Simón, A., Encina, A., Álvarez J. and Acebes, J.L. (2009) Novel type II cell wall architecture in dichlobenil-habituated maize calluses, Planta, 229, 617-631.

Miyamoto, K., Ueda J., Takeda, S., Ida, K., Hoson, T., Masuda, Y. and Kamisaka, S. (1994) Light-induced increase in the contents of ferulic and diferulic acids in cell wall of Avena coleoptiles: its relationship to growth inhibition by light, Physiol. Plant., 92, 350-355.

Nakamura, Y., Wakabayashi, K. and Hoson, T. (2003) Temperature modulates the cell wall mechanical properties of rice coleoptiles by altering the molecular mass of hemicellulosic polysaccharides, Physiol. Plant., 118, 597-604.

Obel, N., Porchia, A.C. and Scheller, H.V. (2002) Dynamic changes in cell wall polysaccharides during wheat seedling development, Phytochemistry, 60, 603-610.

Parvez, M.M., Wakabayashi, K., Hoson, T. and Kamisaka, S. (1997) White light promotes the formation of diferulic acid in maize coleoptile cell walls by enhancing PAL activity, Physiol. Plant., 99, 39-48.

Sakurai, N., Inouhe, M., Masuda, Y. and Kuraishi, S. (1983) Growth regulation in dwarf barley coleoptiles by the minor cell wall components, galactose and mannose, Plant Cell Physiol., 24, 317-325.

Sakurai, N. (1991) Cell wall functions in growth and development. A physical and chemical point of view, Bot. Mag. Tokyo, 104, 235-251.

Saulnier, L., Crepeau, M.-J., Lahaye, M., Thibault, J.-F., Garcia-Conesa, M.T., Kroon, P.A. and Williamson, G. (1999) Isolation and structural determination of two 5,5'-diferuloyl oligosaccharides indicate that maize heteroxylans are covalently cross-linked by oxidatively coupled ferulates, Carbohydr. Res., 320, 82-92.

Saulnier, L. and Thibault, J.-F. (1999) Ferulic acid and diferulic acids as components of sugar-beet pectins and maize bran heteroxylans, J. Sci. Food Agric., 79, 396-402.

Smith, M.M. and Hartley, R.D. (1983) Occurrence and nature of ferulic acid substitution of cell wall polysaccharides in graminaceous plant, Carbohydr. Res., 118, 65-80.

Soga, K., Harada, K., Wakabayashi, K., Hoson, T. and Kamisaka, S. (1999) Increased molecular mass of hemicellulosic polysaccharides is involved in growth inhibition of maize coleoptiles and mesocotyls under 
hypergravity conditions, J. Plant Res., 112, 273-278.

Soga, K., Wakabayashi, K., Kamisaka, S. and Hoson, T. (2003) Growth restoration in azuki bean and maize seedlings by removal of hypergravity stimuli, $A d v$. Space Res., 31, 2269-2274.

Stutte, G.W., Monje, O., Hatfield, R.D., Paul, A.-L., Ferl, R.J. and Simone, C.G. (2006) Microgravity effects on leaf morphology, cell structure, carbon metabolism and mRNA expression of dwarf wheat, Planta, 224, 10381049.

Taiz, L. (1984) Plant cell expansion: Regulation of cell wall mechanical properties, Annu. Rev. Plant Physiol., 35, 585-657.

Tan, K.S., Hoson, T., Masuda, Y. and Kamisaka, S. (1991) Correlation between cell wall extensibility and the content of diferulic and ferulic acids in cell walls of Oryza sativa coleoptiles grown under water and in air, Physiol. Plant., 83, 397-403.

Tan, K.S., Hoson, T., Masuda, Y. and Kamisaka, S. (1992) Involvement of cell wall-bound diferulic acid in light-induced decrease in growth rate and cell wall extensibility of Oryza coleoptiles, Plant Cell Physiol., 33, 103-108.

Urahara, T., Tsuchiya, K., Kotake, T., Tohno-oka, T., Komae, K., Kawada, N. and Tsumuraya, Y. (2004) A $\beta$-(1-4)-xylosyltransferase involved in the synthesis of arabinoxylans in developing barley endosperms, Physiol. Plant., 122, 169-180.

Wakabayashi, K., Hoson, T. and Kamisaka, S. (1997a) Changes in amounts and molecular mass distribution of cell-wall polysaccharides of wheat (Triticum aestivum L.) coleoptiles under water stress, J. Plant Physiol., 151, 33-40.

Wakabayashi, K., Hoson, T. and Kamisaka, S. (1997b) Osmotic stress suppresses the cell wall stiffening and the increase in cell wall-bound ferulic and diferulic acids in wheat coleoptiles, Plant Physiol., 113, 967973.

Wakabayashi, K., Hoson, T. and Kamisaka, S. (1997c) Suppression of cell wall stiffening along coleoptiles of wheat (Triticum aestivum L.) seedlings grown under osmotic stress conditions, J. Plant Res., 110, 311-316.

Wakabayashi, K., Hoson, T. and Kamisaka, S. (1997d) Abscisic acid suppresses the increases in cell wallbound ferulic and diferulic acid levels in dark-grown wheat (Triticum aestivum L.) coleoptiles, Plant Cell Physiol., 38, 811-817.

Wakabayashi, K., Soga, K., Kamisaka, S. and Hoson, T. (2005a) Increase in the level of arabinoxylanhydroxycinnamate network in cell walls of wheat coleoptiles grown under continuous hypergravity conditions, Physiol. Plant., 125, 127-134.

Wakabayashi, K., Soga, K., Kamisaka, S. and Hoson, T. (2005b) Changes in levels of cell wall constituents in wheat seedlings grown under continuous hypergravity conditions, Adv. Space Res., 36, 1292-1297.

Wakabayashi, K., Nakano, S., Soga, K. and Hoson, T. (2009) Cell wall-bound peroxidase activity and lignin formation in azuki bean epicotyls grown under hypergravity conditions, J. Plant Physiol., 166, 947954.

Whetten, R. and Sederoff, R. (1995) Lignin biosynthesis, Plant Cell, 7, 1001-1013. 